\title{
Testicular Mixed Embryonal Carcinoma and Teratoma with Seminoma
}

National Cancer Institute

\section{Source}

National Cancer Institute. Testicular Mixed Embryonal Carcinoma and Teratoma with

Seminoma. NCI Thesaurus. Code C6352.

A malignant mixed germ cell tumor arising from the testis. It is characterized by the presence of a mixture of embryonal carcinoma, a teratomatous component, and a seminomatous component. 